In Situ

Revue des patrimoines

\section{In Situ}

Revue des patrimoines

5 | 2004

Le patrimoine rural ( 1 ère partie)

\title{
Les maisons des Noirs marrons de Guyane
}

\author{
Marie-Pascale Mallé
}

\section{OpenEdition}

Journals

\section{Édition électronique}

URL : http://journals.openedition.org/insitu/2373

DOI : $10.4000 /$ insitu.2373

ISSN : 1630-7305

\section{Éditeur}

Ministère de la culture

\section{Référence électronique}

Marie-Pascale Mallé, « Les maisons des Noirs marrons de Guyane», In Situ [En ligne], 5 | 2004, mis en ligne le 19 avril 2012, consulté le 19 avril 2019. URL : http://journals.openedition.org/insitu/2373 ; DOI : 10.4000/insitu.2373

Ce document a été généré automatiquement le 19 avril 2019

\section{(c) (i) $\odot$}

In Situ Revues des patrimoines est mis à disposition selon les termes de la licence Creative Commons Attribution - Pas d'Utilisation Commerciale - Pas de Modification 4.0 International. 


\title{
Les maisons des Noirs marrons de Guyane
}

\author{
Marie-Pascale Mallé
}

\begin{abstract}
Lors de trois missions menées sur le Maroni entre 1999 et 2003, nous avons fait un repérage systématique des villages djuka et aluku de la rive française, ainsi que des sondages dans un certain nombre de villages situés sur la rive gauche ou dans les îles, généralement surinamiennes, qui obstruent le cours du fleuve. Lors de ces enquêtes rendues difficiles par l'isolement géographique et la barrière de la langue, nous nous sommes attaché à décrire la maison plus que le village qui avait déjà donné lieu à un certain nombre d'enquêtes ethnologiques ${ }^{1}$ et qui est actuellement en pleine mutation (ou abandon) en raison de l'évolution sociale, du travail salarié des hommes, de l'émigration vers les villes. Nous présentons donc ici une étude en cours, une première approche de l'habitat noir-marron qui n'a d'autre ambition que d'insister sur la qualité de l'architecture de ces populations, l'urgence d'en faire un inventaire et la nécessité d'un programme de revalorisation et de protection.
\end{abstract}

\section{Les Noirs marrons}


Figure 1

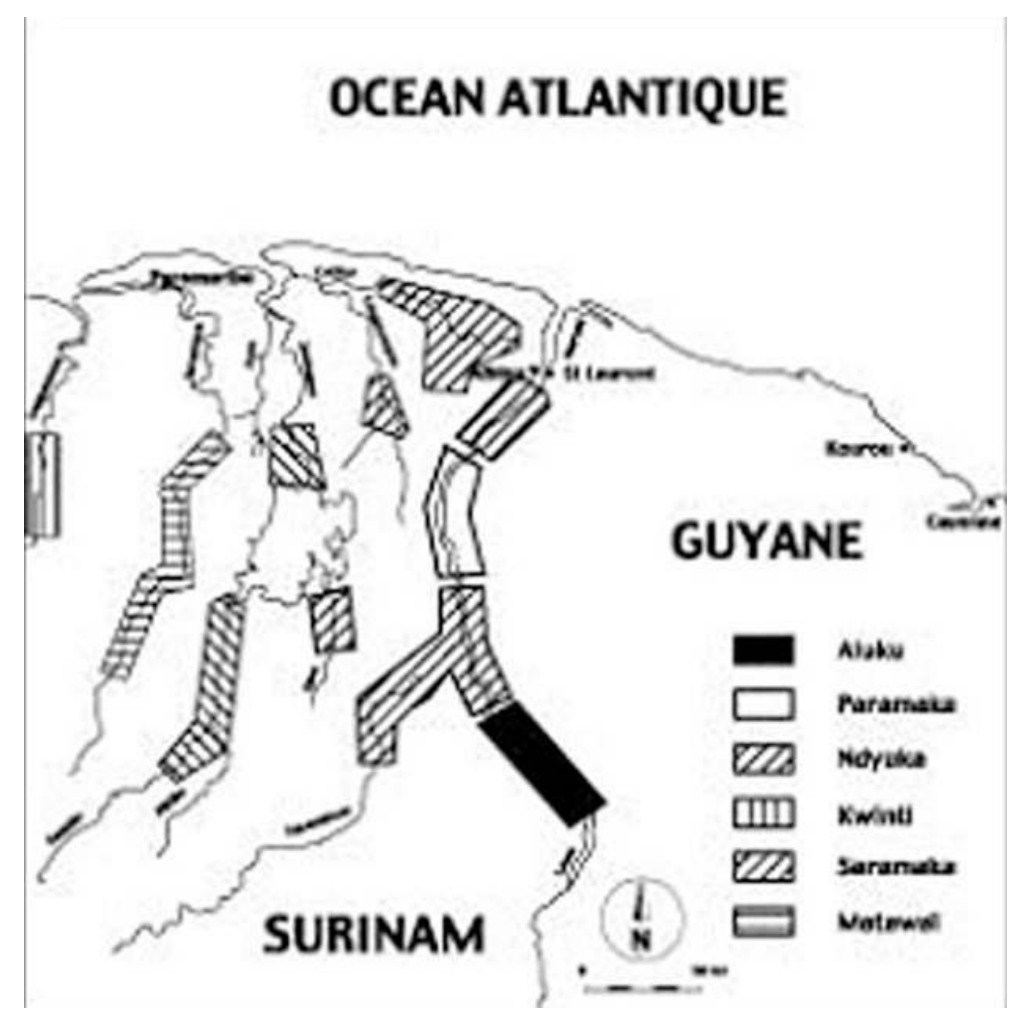

Implantation des noirs marrons en Guyane française et au Surinam

Phot. Inv. M. Heller (c) Inventaire général, ADAGP, 2001

2 C'est ainsi que l'on désignait, non pour leur couleur mais à cause du mot espagnol cimarron (fugitif), les esclaves noirs qui s'échappaient des plantations. Dès la fin du XVII siècle, le marronage prit une grande ampleur au Surinam et ce mouvement s'est poursuivi sans discontinuer pendant deux siècles. Progressivement, les petites bandes d'esclaves fugitifs se sont regroupées en six nations différentes, dont le territoire s'est modifié en fonction de la pression des colons hollandais, des relations diplomatiques entre les colonies française et hollandaise (fig. $\left.\mathbf{n}^{\circ} \mathbf{1}\right)$ et des luttes d'influence entre les différents groupes marrons. 
Figure 2

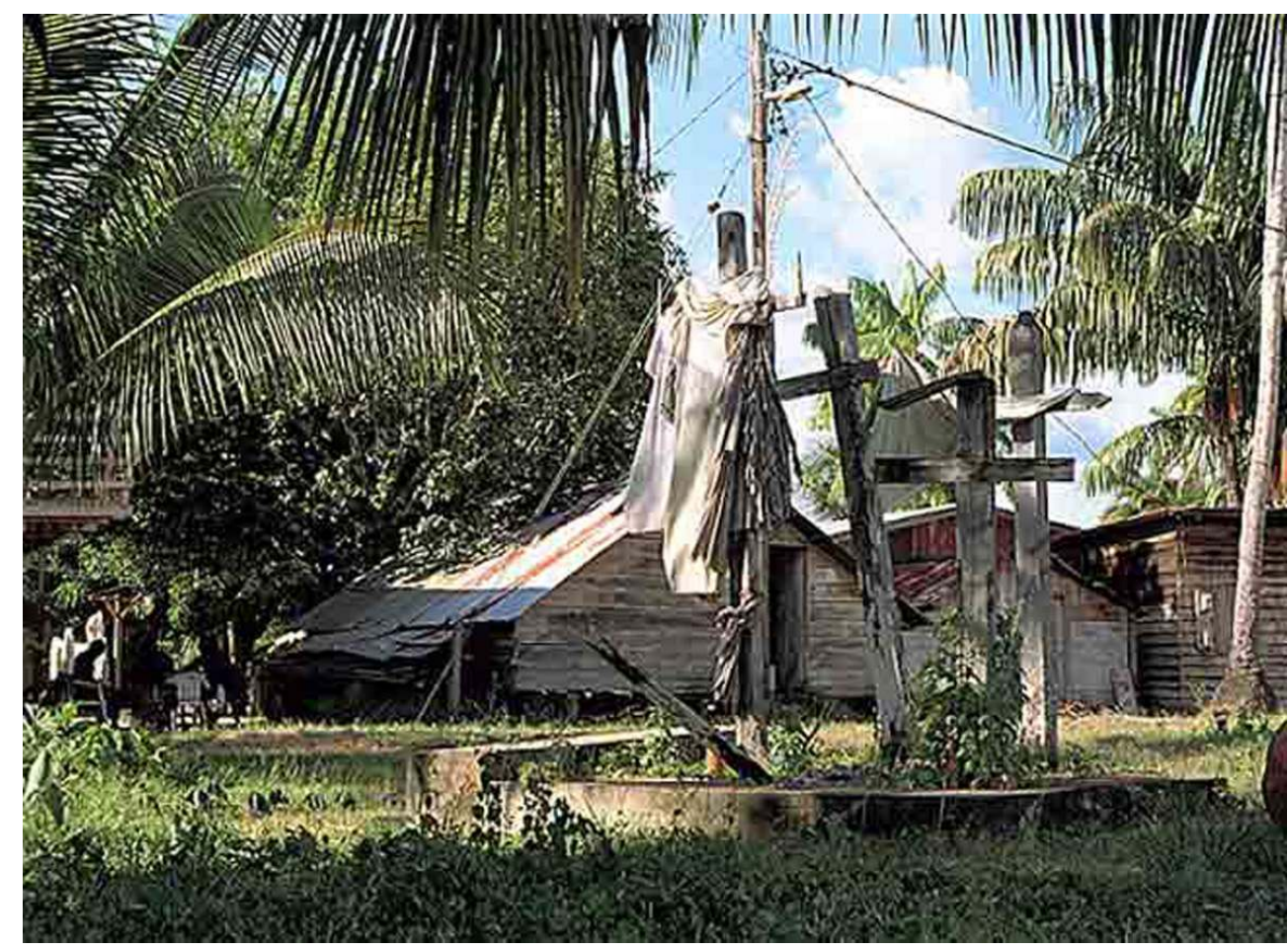

Une rue dans un village Au premier plan, l'autel des ancêtres

Phot. Inv. M. Heller @ Inventaire général, ADAGP, 2001

3 Trois d'entre eux finirent par gagner le bassin du Maroni, ce fleuve long de $500 \mathrm{~km}$ qui constitue la frontière entre la Guyane française et le Surinam (ancienne Guyane hollandaise). Les Bonis ou Aluku occupent depuis la fin du XVIII ${ }^{e}$ siècle le cours du Lawa (actuelle commune de Papaïchton) et plus récemment les alentours d'Apatou (fig. $\mathbf{n}^{\circ} \mathbf{2}$ ). Ils y ont leurs villages (kondré), enracinés par le culte des ancêtres, qui correspondent à un lignage (ou $l o^{2}:$ l'ensemble des personnes, hommes et femmes, descendant d'une même aïeule, se considèrent comme frères sœurs, oncles, tantes, neveux ${ }^{3}$ ). Ils y ont également des campu, habitats temporaires situés à proximité des abattis ${ }^{4}$, occupés de façon intermittente lors des travaux agricoles et abandonnés temporairement ou définitivement en fonction de la rotation des cultures sur brûlis.

Les Djuka ${ }^{5}$ vivent très nombreux sur la commune de Grand-Santi ainsi qu'aux alentours de Saint-Laurent mais, au contraire des Aluku, leurs « grands villages » ne se trouvent pas sur la rive française du Maroni mais sur le cours de l'un de ses affluents côté Surinam, le Tapanahony. Ils n'ont sur la rive droite que des campu. Cependant, la crise économique au Surinam et l'attraction de la politique sociale française font que, depuis les années 1970, leur présence a eu tendance à se pérenniser. A la même période, les Paramaka installés côté surinamien entre Sparwine et Providence ont traversé le Maroni. Les mêmes populations vivent des deux côtés du fleuve. Aujourd'hui, les Noirs marrons dont le nombre augmente rapidement en raison d'une forte natalité et d'une importante immigration, surtout depuis la guerre civile de 1985 au Surinam, représentent près de $20 \%$ de la population de la Guyane française ${ }^{6}$, soit environ 30000 personnes. 


\section{Une architecture remarquable}

5 Originaires de différentes régions d'Afrique, les Noirs marrons ont été en contact avec les colons hollandais avant de s'échapper dans la forêt où ils ont dû composer avec les Amérindiens. Ils y ont développé des cultures originales, à forte dominante africaine, mais intégrant des éléments des autres cultures auxquelles ils ont été confrontés. Leur habitat est en cela remarquable.

En Guyane française, on connaît surtout les maisons des Bonis ou Aluku dont les villages sont, à l'exception de celui de Kotika, du côté français. Les maisons des Djukas en sont très proches. Elles sont aussi harmonieuses dans leurs proportions, aussi ornées et, de plus, conservées en nombre beaucoup plus important. Les exemples observés à Providence ou Apaghi ne donnent qu'une faible idée de la richesse de ce qui est conservé sur le Tapanahony. Il serait urgent de mener sur ce territoire un inventaire systématique des " grands villages » afin de pouvoir comparer efficacement les habitats djuka et aluku.

7 L'installation des Aluku sur la rive droite du Lawa, affluent du haut Maroni, date de la fin du XIXe siècle. De 1815 à 1895, tous les villages Aluku se trouvaient sur la rive gauche, autour du centre de Kotika où l'on peut encore voir aujourd'hui un ensemble architectural remarquable. En 1895, suite à un arbitrage international sur un contesté de frontière qui attribua la rive gauche du Lawa au Surinam, les villages aluku se sont déplacés sur la rive française. Ils ne sont donc pas de très vieille fondation, mais les maisons sont plus récentes encore. Les constructions les plus anciennes que nous avons $\mathrm{pu}$ inventorier sont rarement antérieures au milieu du $\mathrm{XX}^{\mathrm{e}}$ siècle. Cela s'explique par le fait qu'elles sont conçues pour ne durer que le temps d'une vie et sont généralement détruites à la mort de leur occupant (la personne pour laquelle elles ont été construites). Le bâti a tellement évolué qu'il est presque impossible aujourd'hui de se repérer dans les villages avec les plans réalisés par Jean Hurault dans les années 1950-1970.

\section{Maisons d'hommes et maisons de femmes}

8 Les sociétés noir-marron du Maroni sont matrilinéaires. La filiation se fait par les femmes et, en théorie, chacun, homme ou femme, continue à vivre toute sa vie dans son village maternel. Dès qu'un homme a atteint l'âge adulte, il se construit une maison dans son village natal. Lorsqu'un mariage est décidé, l'homme doit construire pour sa future épouse une maison dans le village maternel de celle-ci. Elle y vivra avec ses enfants ${ }^{7}$, dont l'éducation sera de la responsabilité de ses frères, les oncles maternels des enfants. Son mari n'y fera que des séjours temporaires lorsqu'il viendra préparer pour elle l'abattis et vivra le reste du temps dans son propre village maternel, à proximité de sa mère et de ses frères et sœurs adultes, ayant en charge l'éducation de ses propres neveux. En échange de son travail sur l'abattis, sa femme le fournira en couac (semoule de manioc). 
Figure 3

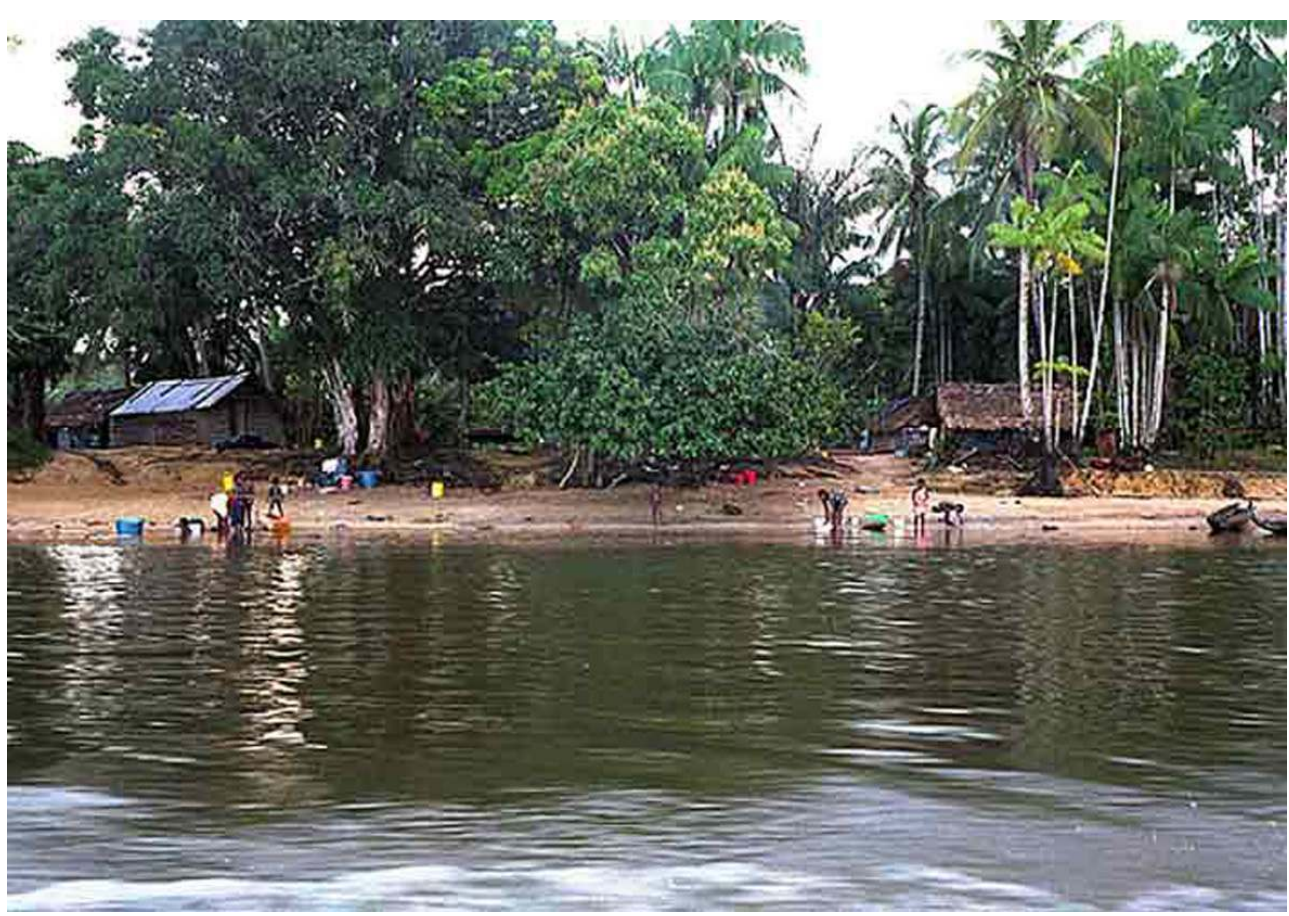

Abords d'un village Djuka (Komondo) sur la rive surinamienne. Importance du fleuve où l'on se baigne et où on lave le linge et la vaisselle

Phot. Inv. M. Heller @ Inventaire général, ADAGP, 2001

Maisons d'hommes et maisons de femmes sont regroupées dans les villages autour de l'habitation de l'aïeule commune. Cet ensemble de constructions, désigné mamapiki, forme souvent une sorte de cercle autour du carbet-cuisine commun où les femmes passent la plus grande partie de leur temps. L'espace familial (pisi), entièrement désherbé, est tenu soigneusement propre et balayé tous les matins. Les villages (kondré) sont donc formés de sous-ensembles correspondant à des entités familiales plus ou moins éloignées de l'aïeule fondatrice. Le lignage (lo) qui peuple un village ou un quartier possède des aménagements communs : les lieux de culte, le carbet de réunion, le carbet mortuaire, la construction où se retirent les femmes pendant leurs règles, et les dégrad ou débarcadères où sont amarrées les pirogues. En effet, tous les villages noir-marron sont construits en bordure de rivière (fig. $\mathbf{n}^{\circ} \mathbf{3}$ ), les seules voies de communication étant le fleuve et ses affluents.

\section{Traditions africaines et amérindiennes}

Les colons français du XVIII ${ }^{\mathrm{e}}$ siècle qui utilisaient la main-d'œuvre servile africaine que leur livraient les bateaux négriers, se plaignaient que leurs esclaves s'entêtassent à dormir dans des cases fermées où ils faisaient du feu pour préparer leur repas, leurs enfants vivant dans une chaleur épouvantable et dans la fumée ${ }^{8}$. On peut imaginer que la situation était sensiblement la même au Surinam. 
Figure 4

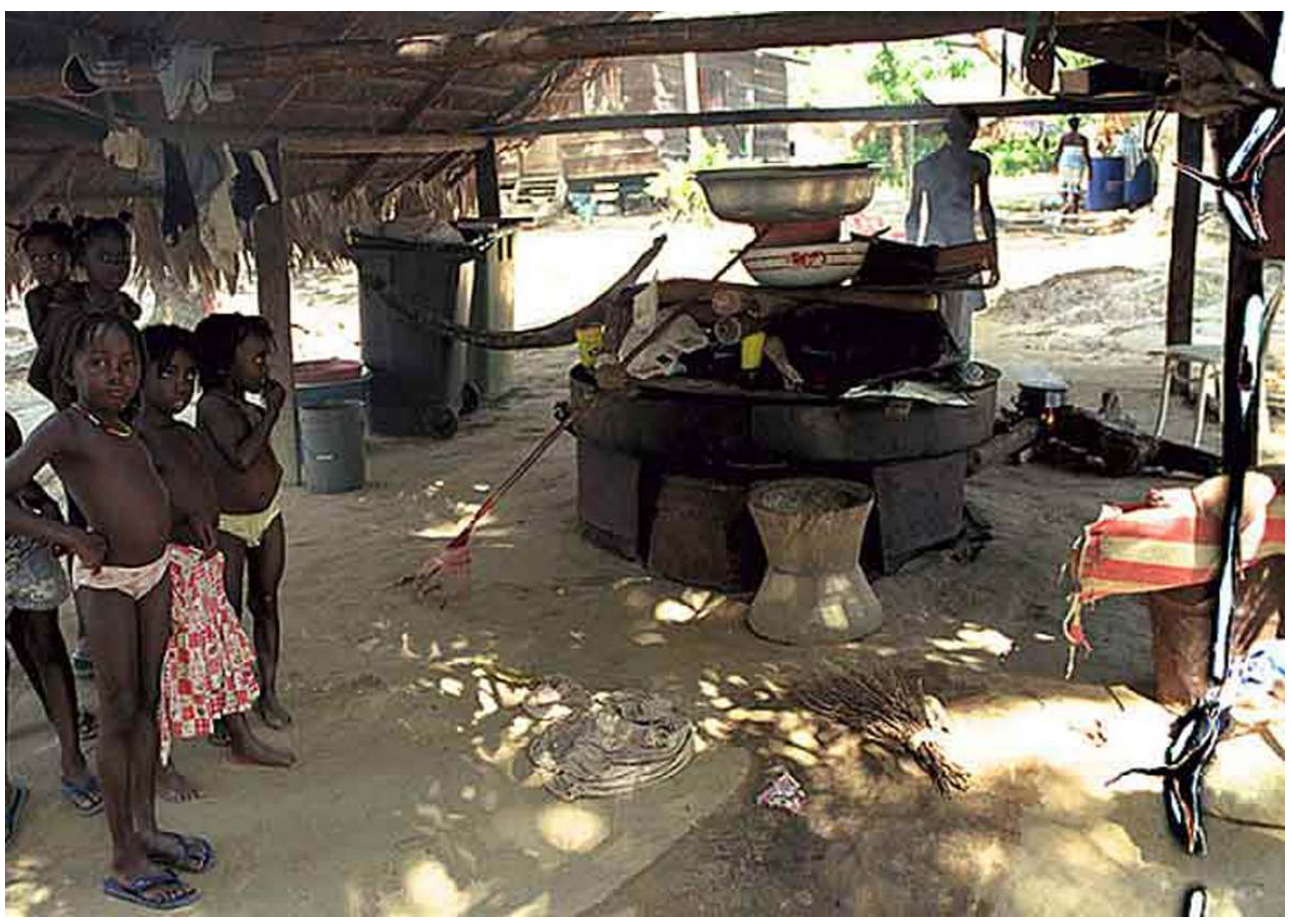

Un carbet-cuisine, vue intérieure. Devant la platine à couac, le mortier à piler le manioc, à droite, au sol, le foyer sur lequel cuit le repas, à gauche, un hamac pour la sieste

Phot. Inv. M. Heller @ Inventaire général, ADAGP, 2001

11 Les esclaves marrons ont pu connaître lors de leur captivité les Amérindiens du littoral, les Kalina, et, en s'enfonçant dans la forêt, ils ont côtoyé les Wayana et les Wayampi. Tous vivaient jour et nuit dans des carbets, constructions sans parois constituées d'une toiture végétale supportée par des poteaux de bois. L'habitat des Noirs marrons installés le long du Maroni et de ses affluents, tel qu'on a pu l'observer au XIXe et au XXe siècle, est resté fidèle à la coutume africaine de dormir la nuit dans une case entièrement close. En revanche, il a emprunté aux Amérindiens le carbet pour se tenir pendant la journée et comme cuisine (fig. $\left.n^{\circ} 4\right)$.

12 Jusqu'à une date récente, la maison noir-marron, divisée en deux petites pièces en enfilade, ne servait que de chambre à coucher et de resserre pour les objets les plus précieux ${ }^{9}$. C'est l'espace où l'on se retirait dès la nuit tombée par peur des esprits. Elle fait toujours l'objet de nombreuses pratiques de protection à propos desquelles on ne nous a pas donné de détails, telles qu'objets prophylactiques accrochés au-dessus de la porte ou signaux végétaux plantés devant la façade principale en rite de purification. Il est fréquent de voir posé à proximité de la porte un grand bol en céramique de fabrication amérindienne ${ }^{10}$, dans lequel trempent des plantes avec lesquelles on s'asperge avant de passer le seuil. 
Figure 5

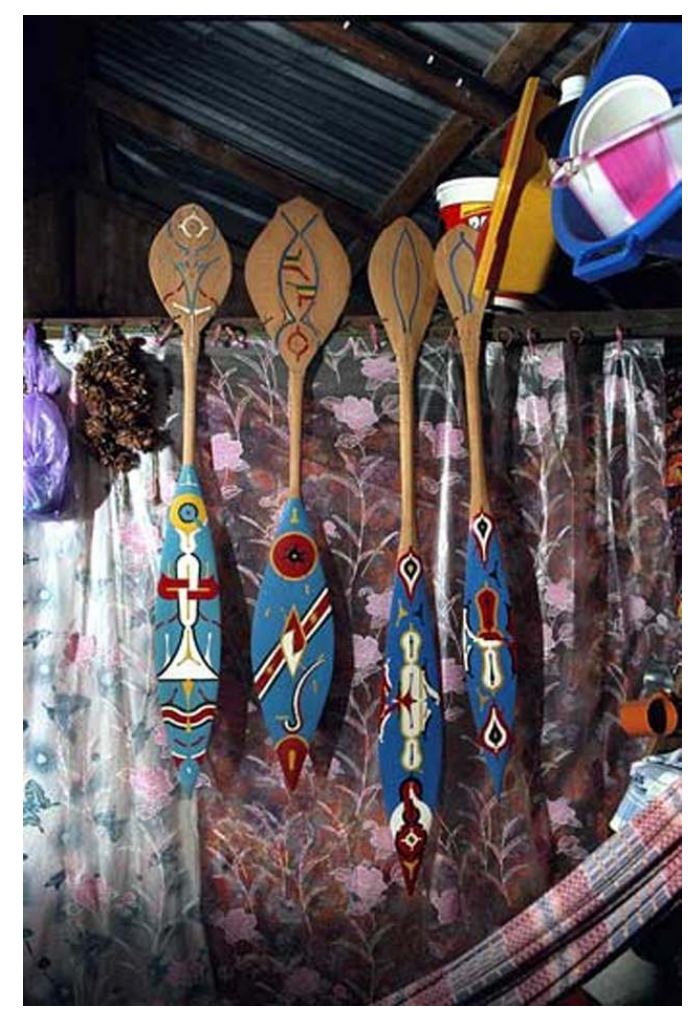

Vue intérieure d'une maison djuka : au mur sont accrochés des rideaux de douche décorés, probablement rapportés de Paramaribo, ainsi que les pagaies et les bancs sculptés réalisés par le mari comme cadeaux à son épouse. Les ustensiles en plastique sont rangés sous la toiture. Le seul ameublement de cette pièce est le hamac

Phot. Inv. M. Heller @ Inventaire général, ADAGP, 2001

13 Les femmes dorment avec leurs enfants dans la maison que leur mari leur a construite et qu'elles gardent en cas de séparation. Lorsque leur mari leur rend visite, elles envoient les enfants les plus grands dormir chez leurs tantes. La maison n'est meublée que de hamacs, parfois d'une couche en bois, et d'objets personnels ou précieux suspendus au mur (fig. $\mathbf{n}$ - 5) comme autant de décorations: bancs sculptés et pagaies peintes par le mari, vêtements, tissus brodés.

Les repas sont préparés sous le carbet-cuisine, sur un petit foyer au sol, et pris en fonction de la saison sous le carbet, sous un manguier, etc. Tous les ustensiles liés à la préparation des aliments : râpes, mortiers, couleuvres à manioc, touques renfermant les provisions de couac ou de riz sont conservées sous le carbet-cuisine. Il n'existe pas de greniers: les récoltes se faisant tout au long de l'année, au fur et à mesure des besoins, on ne stocke que de petites quantités. Les Noirs marrons ne font plus de feu à l'intérieur des cases. La fabrication du couac et la préparation des repas se fait dans ce carbet commun, d'ailleurs désigné comme la maison du feu (faya osu). Le mamapiki peut également posséder en commun un carbet de réunion et un carbet sous lequel on stocke du matériel (par exemple les bidons d'essence), un poulailler, des arbres fruitiers. 


\section{Les maisons du milieu du $\mathrm{XX}^{\mathrm{e}}$ siècle.} dizaines d'exemples, souvent en mauvais état. On hésite à qualifier cette architecture de « traditionnelle » étant donné son caractère récent, mais elle l'est en ce sens qu'elle ne se conforme pas aux modèles occidentaux.

Figure 6

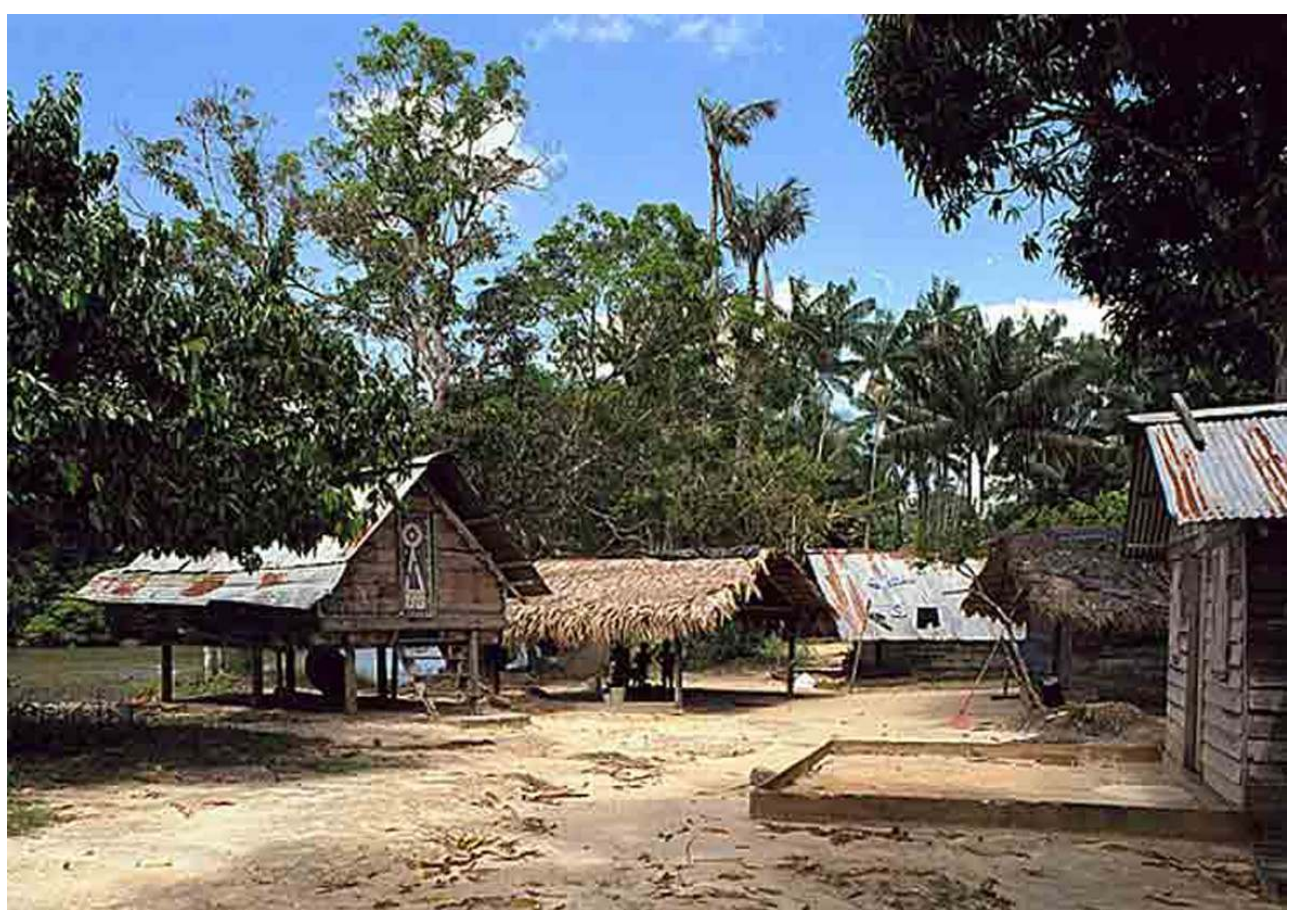

Maisons sur pilotis et maisons au sol entourent le carbet commun

Phot. Inv. M. Heller (c) Inventaire général, ADAGP, 2001 peuvent être soit construites au sol, sur un solin en terre battue légèrement surélevé pour faciliter l'écoulement de l'eau, soit sur pilotis. Ce dernier type est bien entendu plus fréquent dans les zones inondables comme Assissi, mais on trouve couramment les deux formes côte à côte dans les mêmes villages. Les maisons sur pilotis sont construites et ornées de la même façon que les maisons au sol. Simplement, un petit escalier extérieur et parfois un balcon donnent accès au logis surélevé de $1 \mathrm{~m}$ à $1,50 \mathrm{~m}$ (fig. $\mathbf{n}^{\circ}$ 6).

17 Toutes sont de dimensions réduites : 3 à $4 \mathrm{~m}$ de large sur 5 à $6 \mathrm{~m}$ de long, pour une hauteur sous faitage de $3 \mathrm{~m}$ environ. Elles sont construites en planches épaisses, dressées à l'herminette et rabotées, en bois d'essences variées que nous avons rarement identifiées. Les pièces de bois en contact avec le sol, comme la planche placée à la base de la construction ou les 6 poteaux fichés en terre qui raidissent les cloisons latérales et supportent les pignons, sont en bois imputrescible.

18 La toiture à deux longs pans, à pente très forte, recouverte de feuilles de waï ${ }^{11}$ comme celle des carbets des indiens Wayana ${ }^{12}$, déborde de la façade principale de 50 à 80 centimètres pour former une sorte d'auvent. 
Figure 7

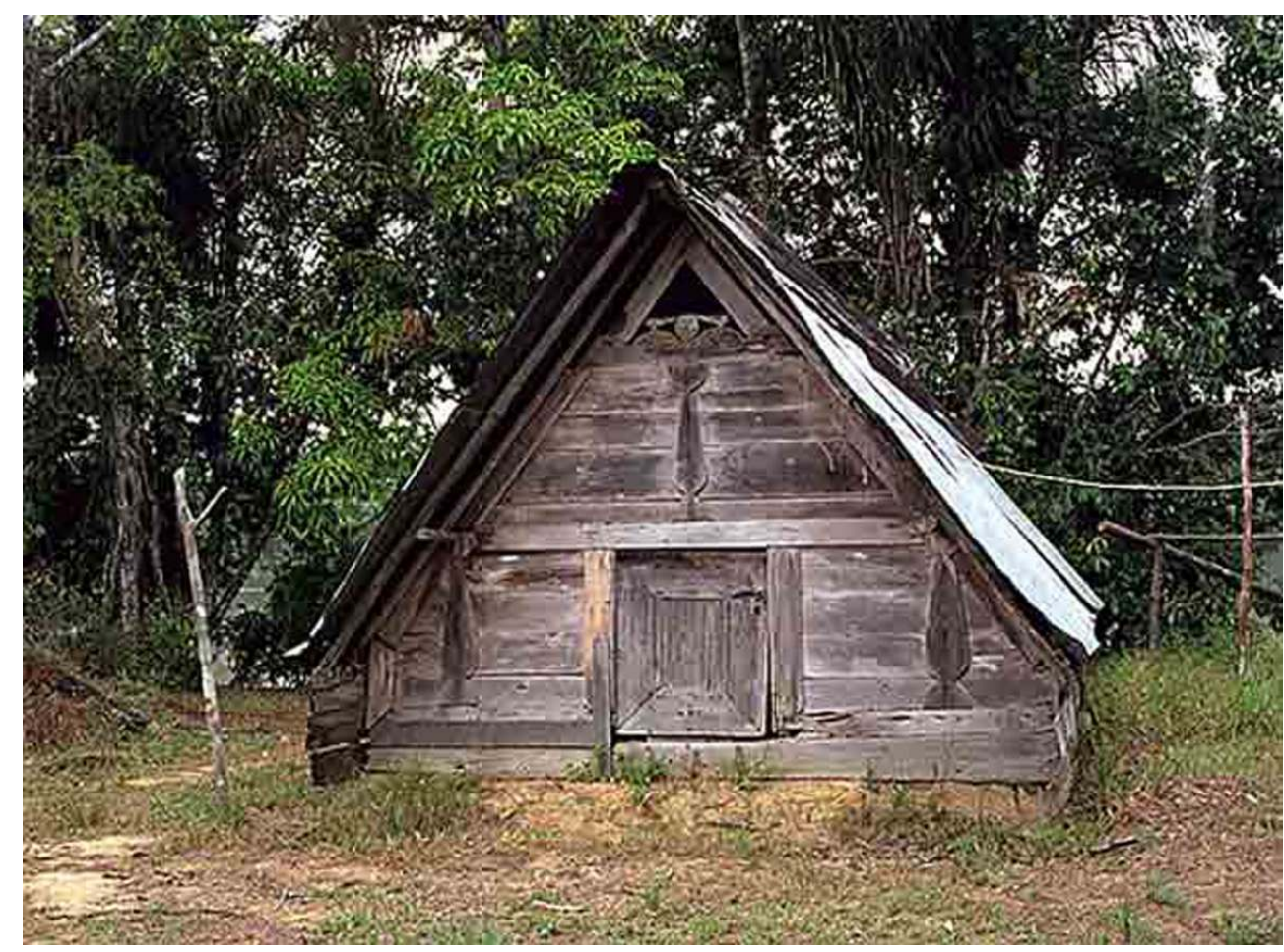

Une façade très classique dans sa composition et ses proportions. Noter le faux-entrait et le poinçon et la pointe ajourée avec son décor découpé

Phot. Inv. M. Heller @ Inventaire général, ADAGP, 2001

19 La charpente en bois est extrêmement légère: une panne faîtière et deux paires de pannes latérales de faible section ( 6 à $8 \mathrm{~cm}$ de diamètre) qui supportent les baguettes servant de chevrons sur lesquelles on fixe les bandes de feuilles de waï. Les pignons des deux façades et de la cloison centrale servent, si l'on peut dire, de fermes de charpente. Faute de mieux, nous donnerons aux différentes pièces les constituant les noms utilisés par les charpentiers en France, mais il ne s'agit que de planches et l'on ignore s'il y a une quelconque influence européenne dans l'utilisation de ce type d'assemblage. Le pignon proprement dit est toujours formé d'un entrait et de deux arbalétriers, plus rarement d'un faux-entrait ou d'un poinçon. Cette structure chevillée comporte un remplissage en planches pleines ou ajourées ou en feuilles de waï. Le triangle du pignon proprement dit repose généralement sur les pannes intermédiaires de la toiture et l'entrait sert habituellement de linteau à la porte d'entrée, ce qui donne à la façade des maisons aluku un dessin et des proportions très caractéristiques (fig. $\mathbf{n}^{\circ} \mathbf{7}$ ).

20 Les pièces de bois qui constituent le triangle du pignon sont chevillées et non ligaturées contrairement à celles des carbets amérindiens, ce qui a été interprété comme un emprunt au savoir-faire européen lors de la captivité dans les plantations du Surinam ${ }^{13}$. De même, on suppose que les esclaves noirs ont appris à cette occasion l'usage des outils en métal qu'ils utilisent pour la construction de leurs pirogues et de leurs maisons (en particulier le sabre d'abattis, la hache, l'herminette et le rabot). Après s'être échappés, ils allaient en voler lors de leurs raids contre les plantations; les colons hollandais leur en ont ensuite fourni sous forme de tribut, après la signature des traités de paix. 
21 Le triangle du pignon est une partie extrêmement valorisée de la maison (fig. $\mathbf{n}^{\circ} \mathbf{8}$ ). Il semble souvent en remploi, le triangle entier ayant été récupéré sur une construction abandonnée (fig. $\mathbf{n}^{\circ}$ 9).

22 C'est lui qui porte la plus grande partie du décor sous forme de découpes ajourées ou de motifs peints. Il a d'ailleurs donné son nom à un style de composition géométrique, le kopo futu tembé, que l'on utilise pour orner différents objets de la vie quotidienne en particulier les bancs.

23 C'est la très forte pente de la toiture qui donne à la maison aluku sa silhouette si particulière. Les maisons du début du $\mathrm{XX}^{\mathrm{e}}$ siècle ne comportaient pas de parois latérales ; le long pan du toit venait jusqu'à terre et n'était arrêté que par une planche partiellement encastrée dans le sol. Il n'existe presque plus d'exemples de constructions de ce type (fig. $\left.\mathbf{n}^{\circ} \mathbf{1 0}\right)$.

Figure 8

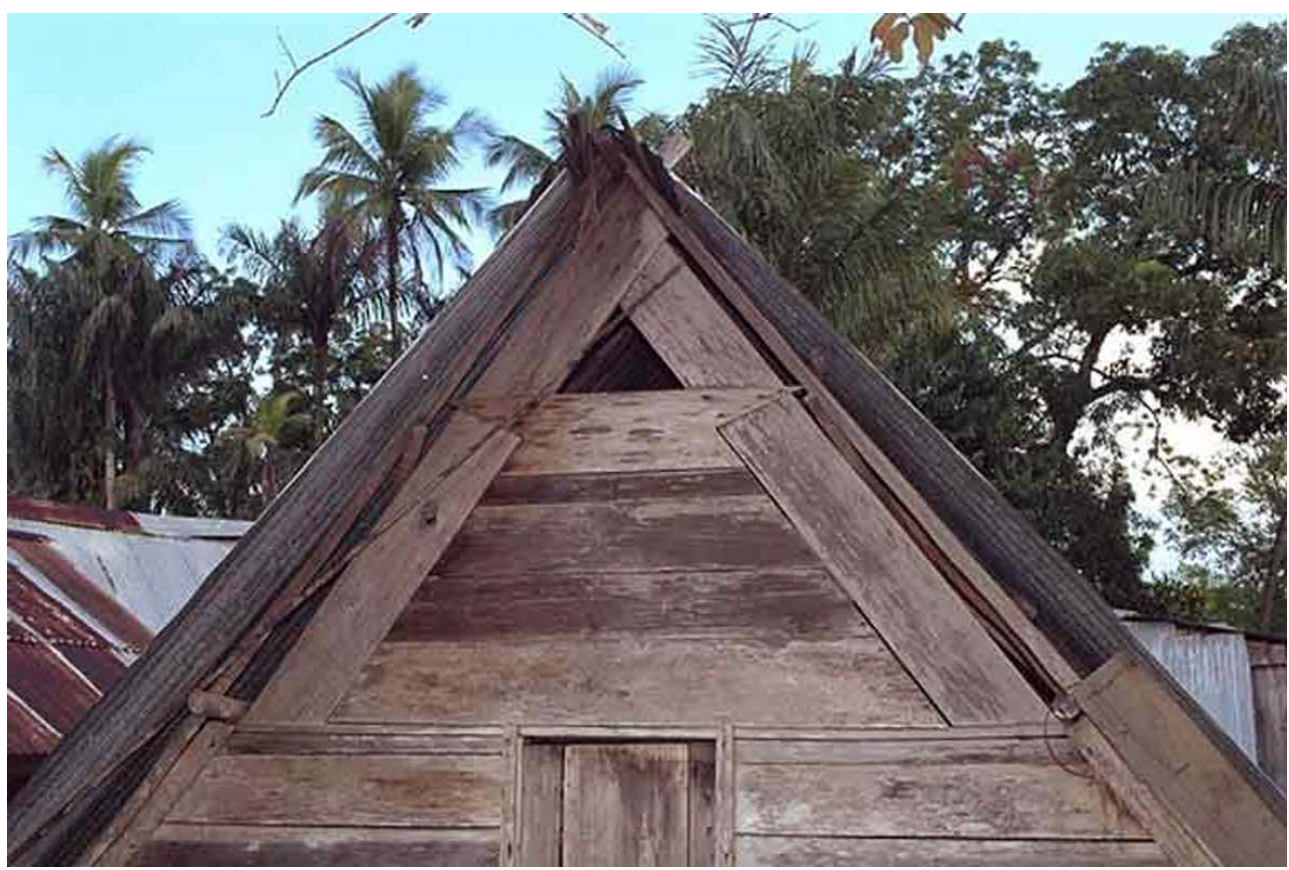

Pignon formé de deux arbalétriers, d'un entrait et d'un faux-entrait avec un assemblage assez savant Phot. Inv. M. Heller @ Inventaire général, ADAGP, 2001 
Figure 9

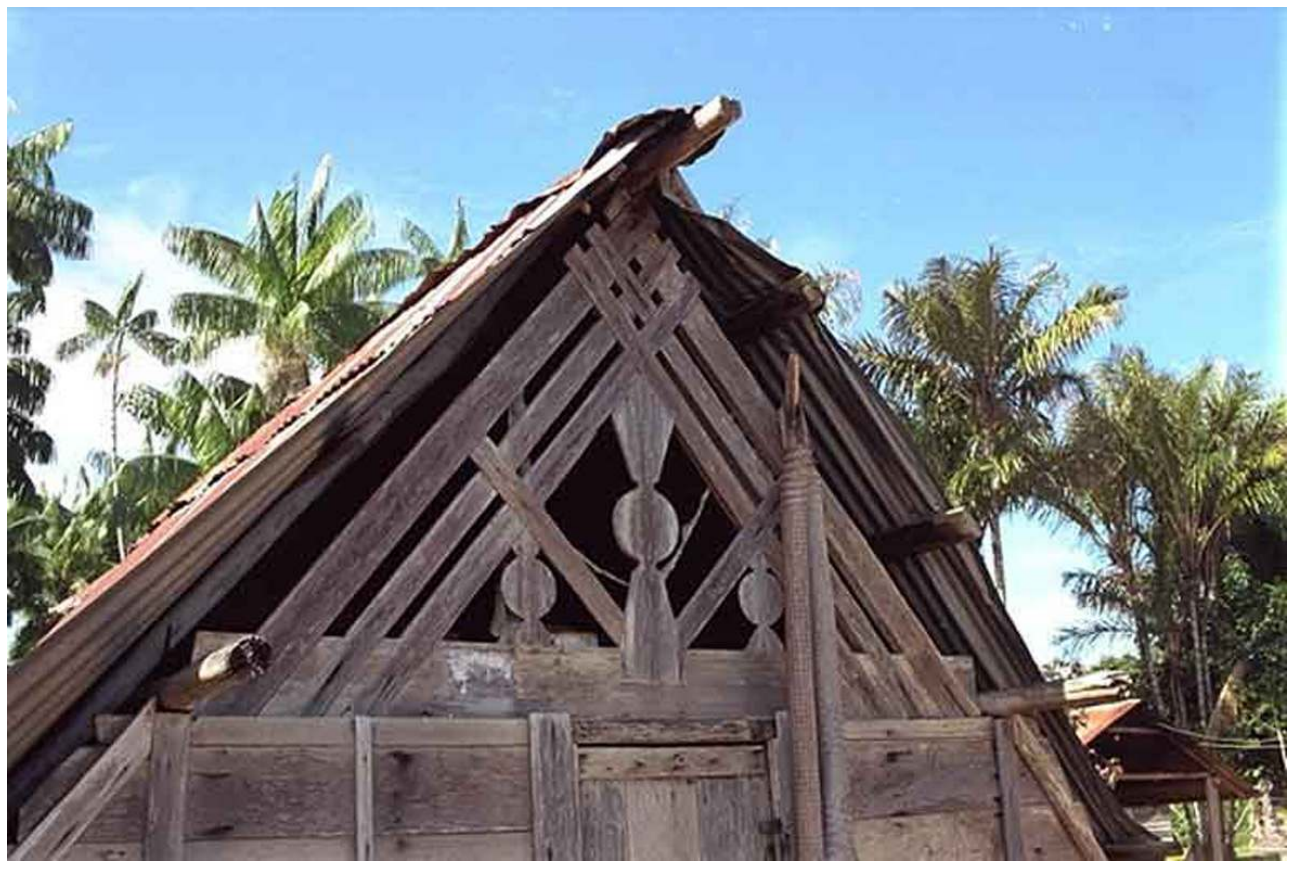

Pignon découpé, probablement en remploi

Phot. Inv. M. Heller @ Inventaire général, ADAGP, 2001

Figure 10

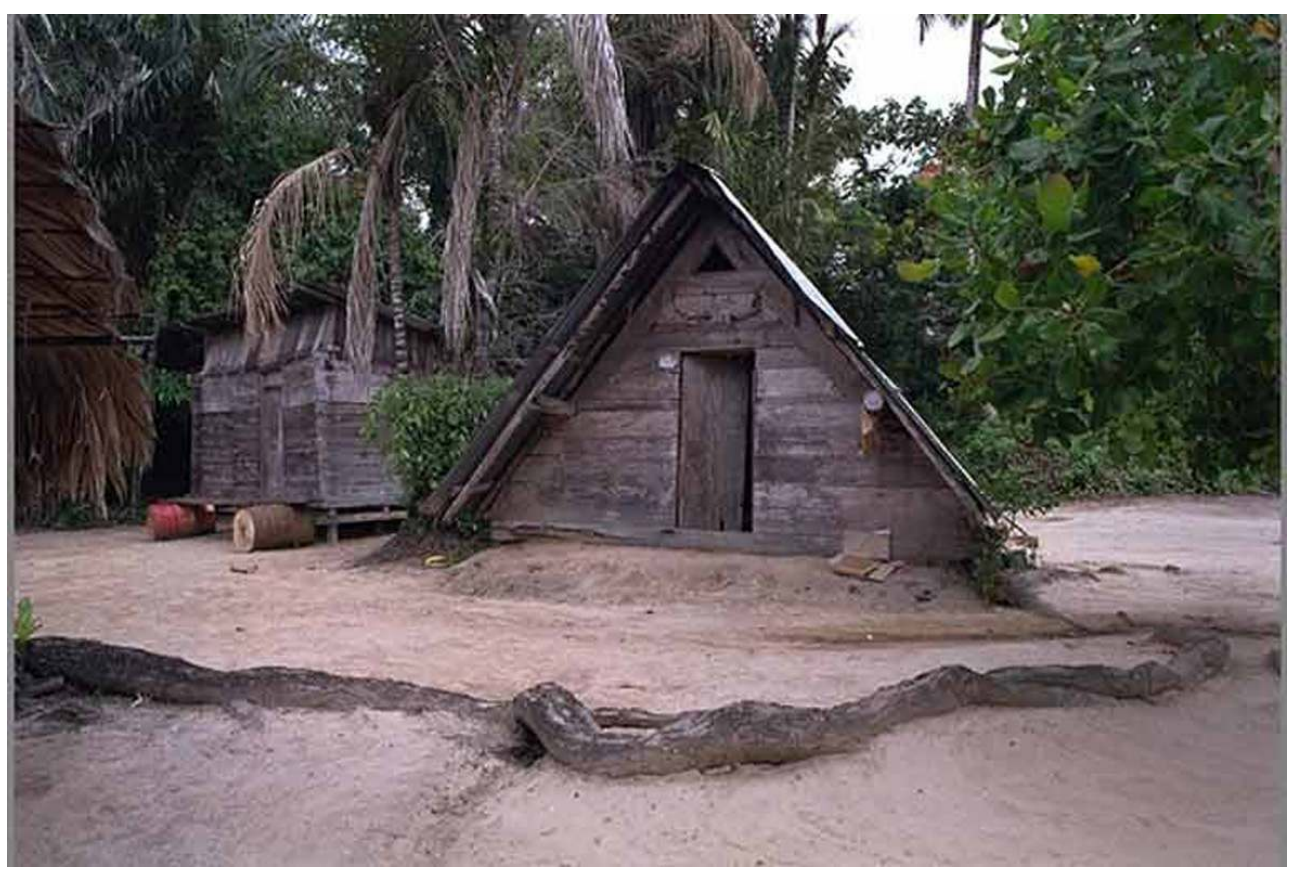

Maison probablement ancienne dont les parois latérales sont réduites à une seule planche. La porte d'entrée a été modifiée pour atteindre une taille européenne

Phot. Inv. M. Heller (c) Inventaire général, ADAGP, 2001 
24 cinquantaine de centimètres de hauteur qui se prolongent en avant de la façade (fig. $\mathbf{n}$ - 11) sur la largeur du débord de toit.

25 La maison aluku de cette époque est donc toujours un bâtiment bas, dans lequel on ne se
tient debout qu'au centre et courbé en deux sur les côtés. La porte elle-même, de moins
d'un mètre de hauteur, oblige à pénétrer courbé dans la maison (fig. $\mathbf{n}^{\circ} \mathbf{1 2}$ ). Figure 11

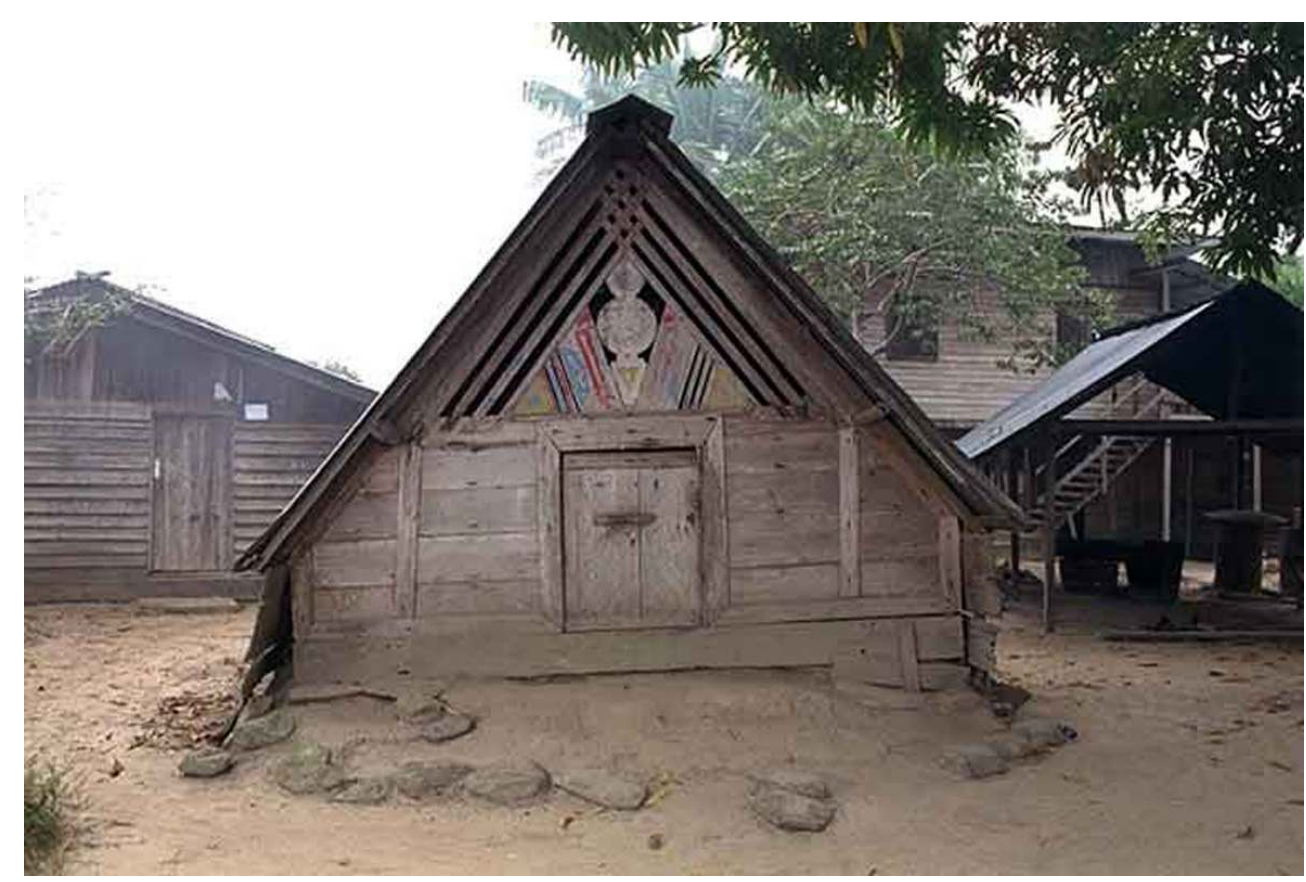

Cette maison et la suivante (voir la figure 12) présentent les mêmes proportions ainsi qu'un pignon découpé et peint. Elle est située dans un village, l'autre dans un campu

Phot. Inv. M. Heller (C) Inventaire général, ADAGP, 2001 
Figure 12

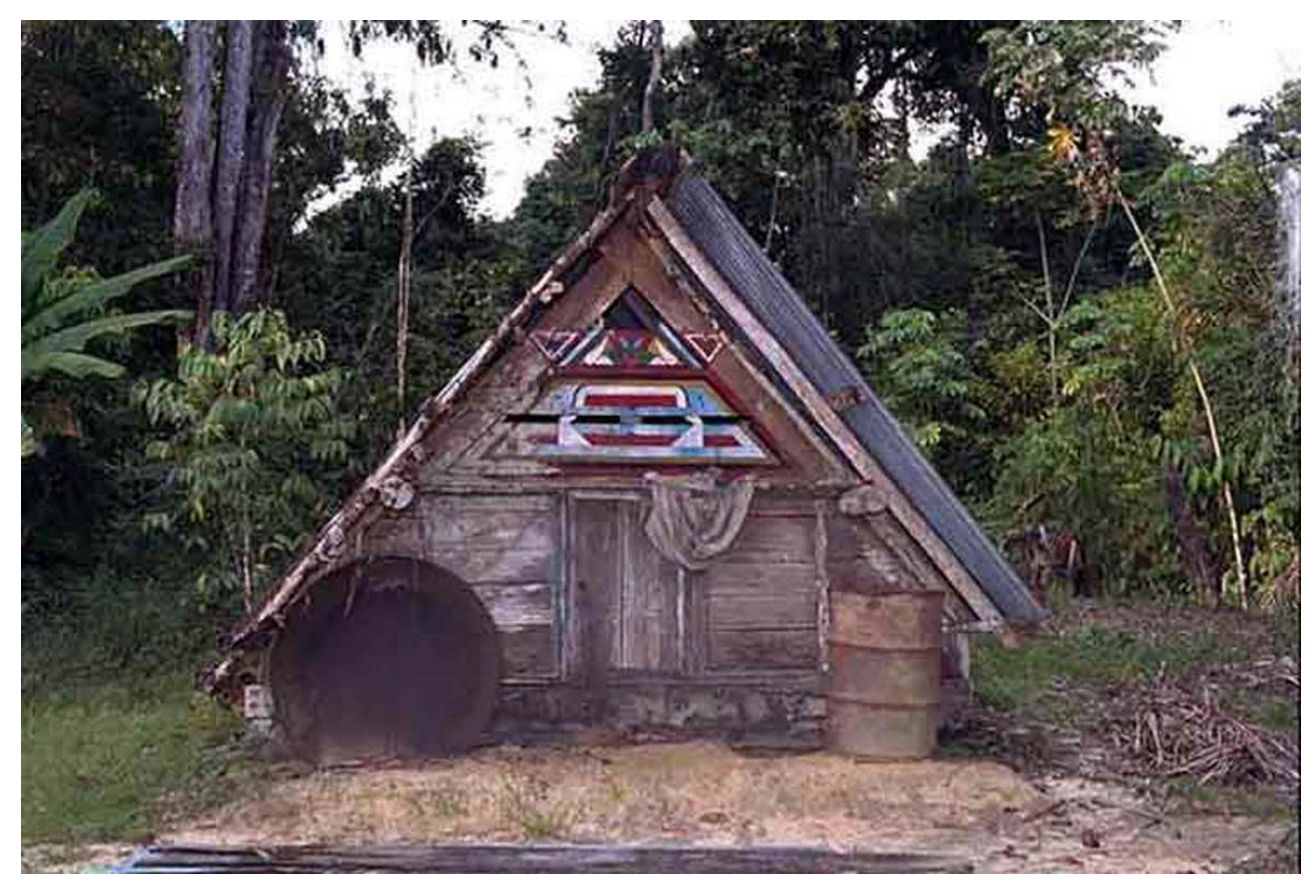

Maison du même type que la précédente (voir la figure 11) mais située dans un campu

Phot. Inv. M. Heller (c) Inventaire général, ADAGP, 2001

La tendance, dans la deuxième moitié du XXe siècle, est à l'augmentation progressive des parois latérales et de la porte d'entrée et à la diminution de la pente de toiture. Les maisons ont ainsi des hauteurs sous toiture plus proches de celles en usage en Europe. On a avancé l'hypothèse que ce phénomène général s'explique par le remplacement de la feuille de waï par la tôle ondulée, ce dernier matériau ne nécessitant pas une pente aussi importante ${ }^{14}$. (fig. $\mathbf{n}^{\circ}$ 13) Ce n'est que partiellement vrai : les Amérindiens qui emploient la feuille de waï donnent à leur toiture une pente beaucoup moins forte que les Noirs marrons. Par ailleurs, nous avons recensé un grand nombre de constructions à couverture végétale dont la silhouette se rapproche de la maison européenne. Il semble qu'avec la tôle ondulée, se soient diffusés de nouveaux modes d'habiter plus proches des normes européennes. Un bon exemple de cette évolution est donné par les maisons construites par les Aluku à Apatou (fig. $\mathbf{n}^{\circ} \mathbf{1 3}$ ), commune proche de Saint-Laurent. Elles sont plus hautes que celles vues sur le Lawa et ont une porte d'environ $1,80 \mathrm{~m}$ de hauteur qui permet d'entrer debout; elles ne comportent parfois qu'une seule pièce et commencent à être meublées autrement que la maison traditionnelle (lit, télévision, etc.). 
Figure 13

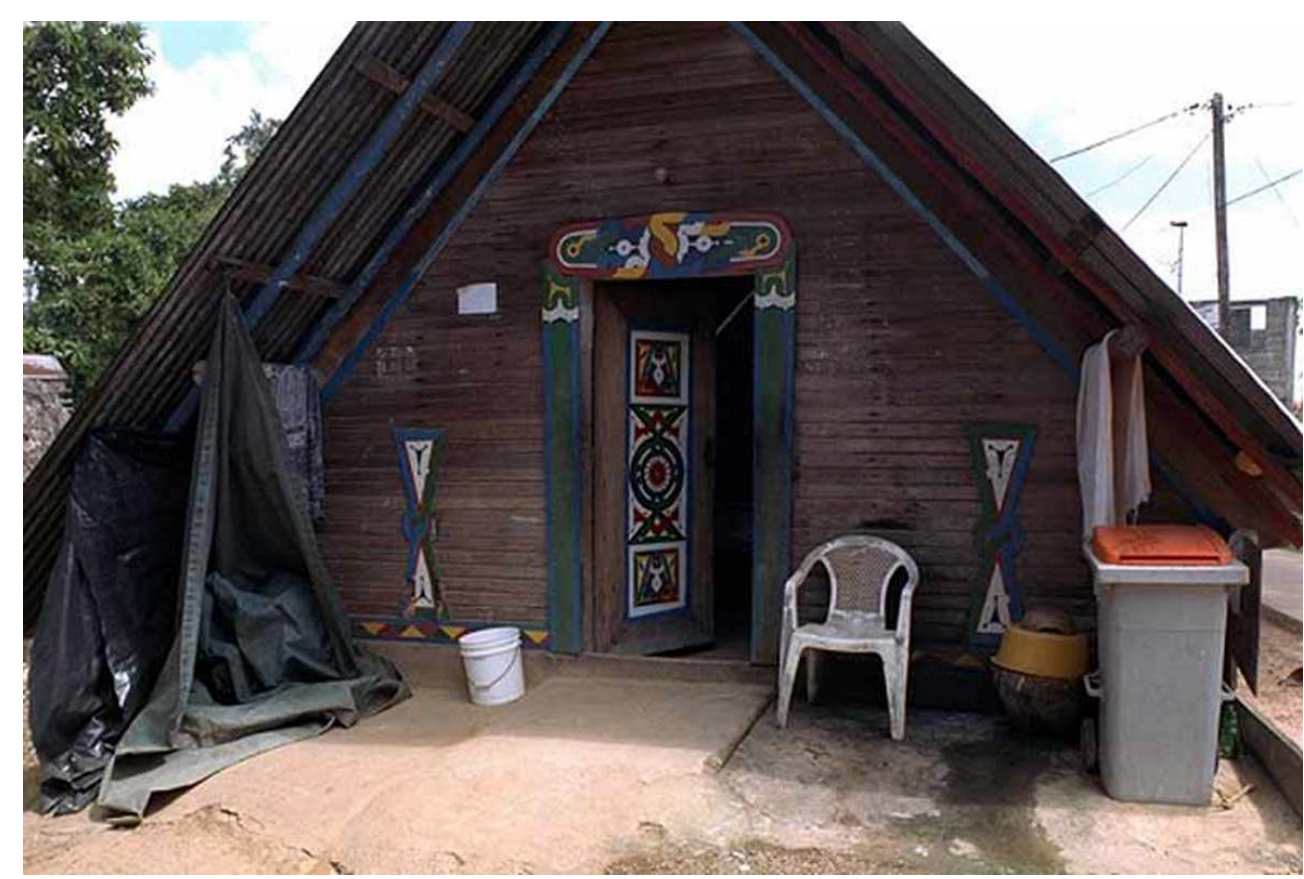

Maison aluku à Apatou. Cette construction récente, plus vaste et plus haute que les maisons traditionnelles, a été réalisée en lambris industriel mais a conservé la forte pente de toiture et l'auvent. II n'y a plus de rupture entre le pignon proprement dit et le reste de la façade, mais des éléments du décor traditionnel ont été repris : la frise peinte à la périphérie de la façade, le tembé peint sur la porte et le linteau, les deux éléments verticaux qui imitent les faux pilastres placées à la verticale des pannes des constructions plus anciennes représentent le motif Kelewa, symbole du corps féminin, souvent utilisé dans les pignons des maisons de femme

Phot. Inv. M. Heller @ Inventaire général, ADAGP, 2001

Plus que le remplacement d'un matériau par un autre, nous pensons que l'évolution des formes architecturales est conditionnée par le mode d'habiter. On le constate par exemple dans le fait que la porte qui était autrefois le seul accès, la ventilation étant assurée par la découpe du pignon, est de plus en plus souvent encadrée par deux petites fenêtres et que le pignon, toujours décoré, n'est plus ajouré.

\section{Le décor}

Comme tous les objets de la vie quotidienne, les maisons noir-marron sont extrêmement décorées. C'est vrai pour les maisons de femmes, où le futur mari met toute son habileté à témoigner son amour, comme pour les maisons d'hommes. Le décor concerne essentiellement la façade principale, dans une moindre mesure la cloison centrale qui sépare la maison en deux pièces, pas du tout la façade arrière.

Le goût a évolué, mais il faut noter que, d'une manière générale, l'ornementation souligne fortement la structure de la construction : on trouve souvent une baguette moulurée ou une frise peinte soulignant la périphérie de la façade ainsi que le tour de la porte et éventuellement des fenêtres. A la verticale des pannes de la toiture sont placés des sortes de pilastres galbés en bois découpé. Les huisseries de porte sont gravées de motifs géométriques. Mais c'est sur le pignon que se concentre l'essentiel du décor (fig. $\mathbf{n}^{\circ} 14$ et 15). 
Figure 14

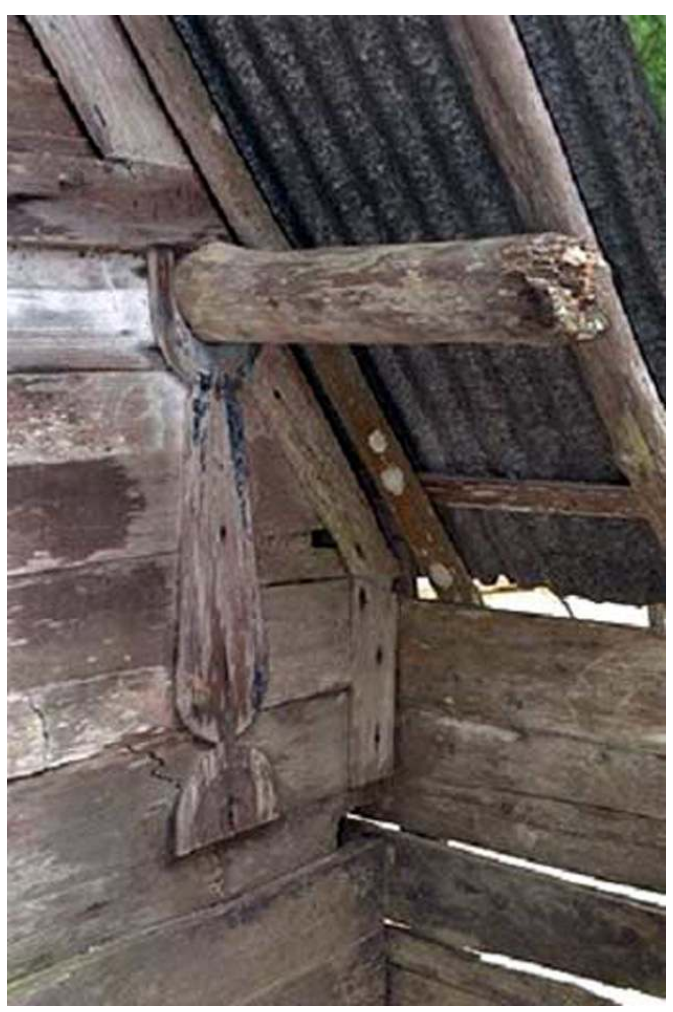

Détail de construction : le pignon repose sur les pannes intermédiaires elles-mêmes soulignées par des pièces de bois découpé en forme de balustre

Phot. Inv. M. Heller @ Inventaire général, ADAGP, 2001 
Figure 15

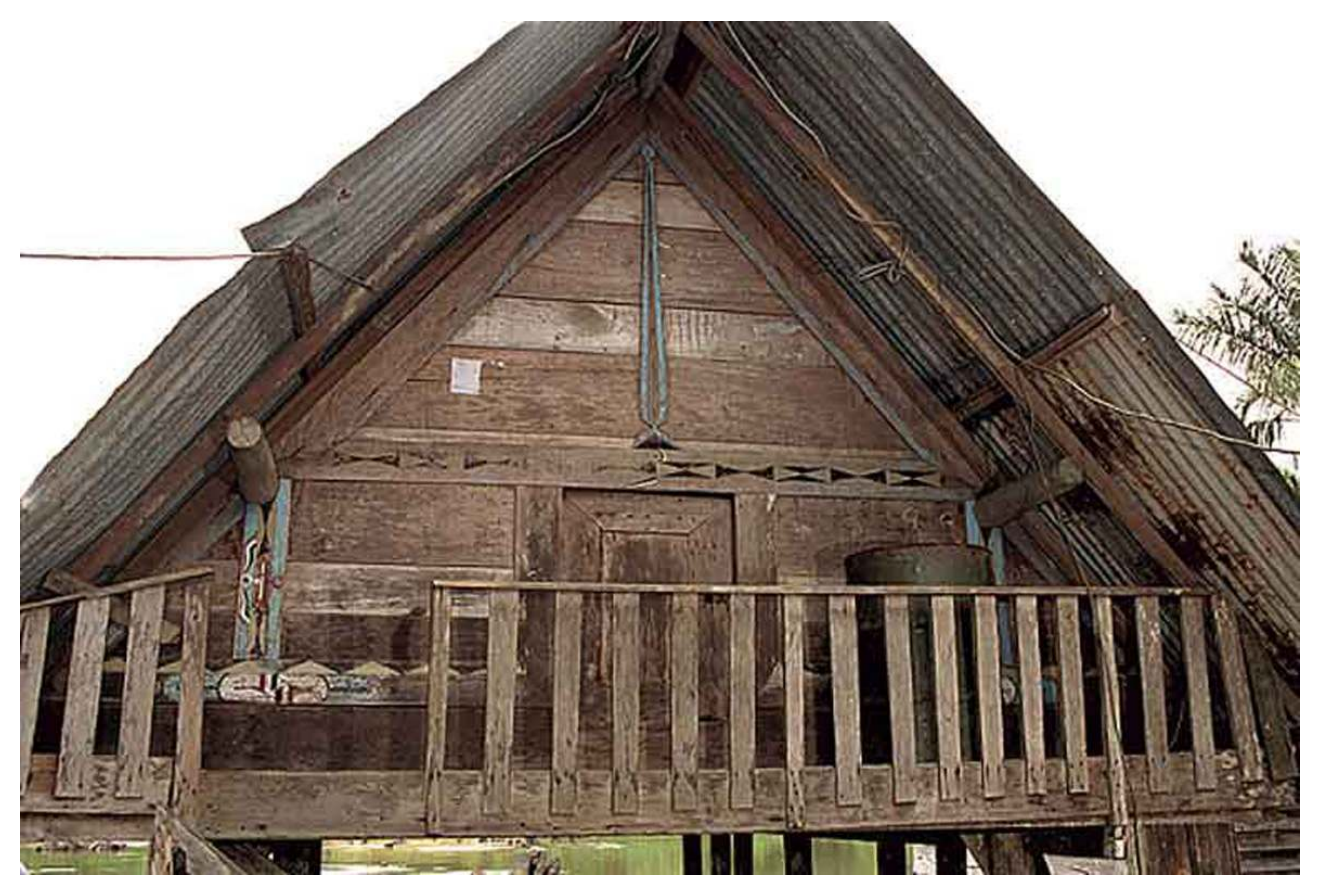

Maison sur pilotis avec accès par un escalier extérieur et un balcon. La façade est construite sur le même principe que celles des maisons au sol. Le pignon bien dessiné comporte un poinçon

Phot. Inv. M. Heller ( Inventaire général, ADAGP, 2001

D'après Jean Hurault, pendant la première moitié du XXe siècle, la mode était au décor de motifs découpés et ajourés en bois de couleurs différentes. Nous avons encore pu en photographier quelques beaux exemples, souvent sur des maisons en ruines. Au milieu du $\mathrm{XX}^{\mathrm{e}}$ siècle, avec la diffusion des peintures industrielles, les pignons se sont ornés de motifs découpés et peints de couleurs vives à caractère symbolique et sexuel, particulièrement sur les maisons de femmes où l'on trouve des motifs géométriques qui seraient une abstraction du corps féminin, du nombril ou du sexe ou des motifs évoquant l'union sexuelle. Il existe encore de très beaux exemplaires de maisons décorées de la sorte à Kotika, à Loka, à Assissi, à Boniville. Mais ces bâtiments qui auraient été construits au milieu du XXe siècle (Jean Hurault en a photographié une en construction vers $1950^{15}$ ) sont aujourd'hui souvent à l'abandon et en très mauvais état.

31 La porte de petite taille ( $60 \mathrm{~cm} \times 90 \mathrm{~cm}$ environ) présente également un riche décor (fig. $\mathbf{n}$ - 16) : soit par sa structure à panneaux rentrants et coupes d'onglet, soit par sa sculpture à motifs d'entrelacs appelés tembé.

Les motifs décoratifs (fig. $\mathbf{n}^{\circ}$ 17) ne sont peints que dans les constructions contemporaines où la porte est de taille européenne. 
Figure 16

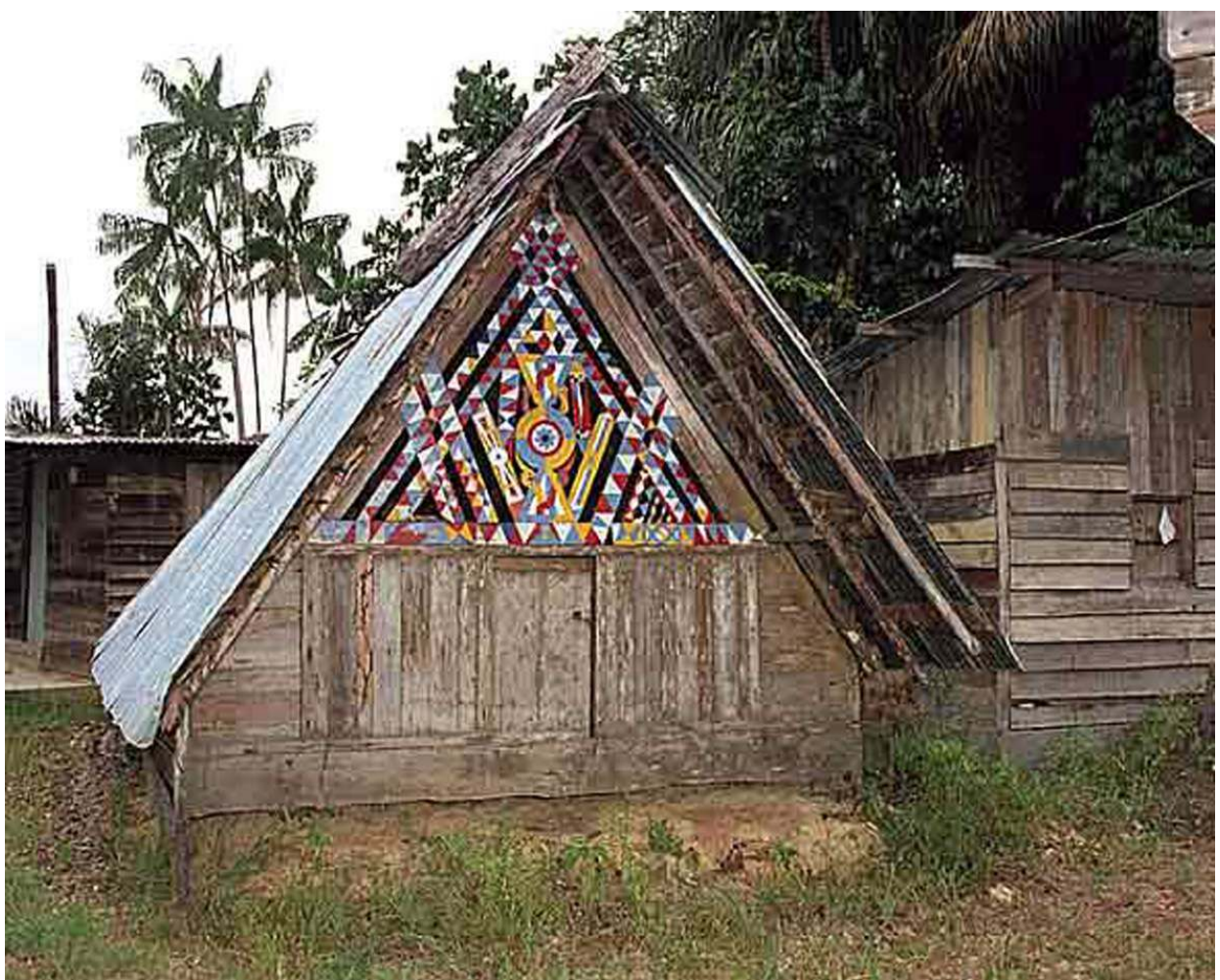

Une maison aluku de Loka (hameau de Papaïchton). Le remplissage du pignon en planches

découpées, ajourées et peintes comporte en son centre le motif Kelewa qui représenterait le corps féminin, la porte est sculptée d'un motif d'entrelacs dit tembé, peu visible sur cette photo. A droite et derrière, des constructions contemporaines

Phot. Inv. M. Heller @ Inventaire général, ADAGP, 2001 
Figure 17

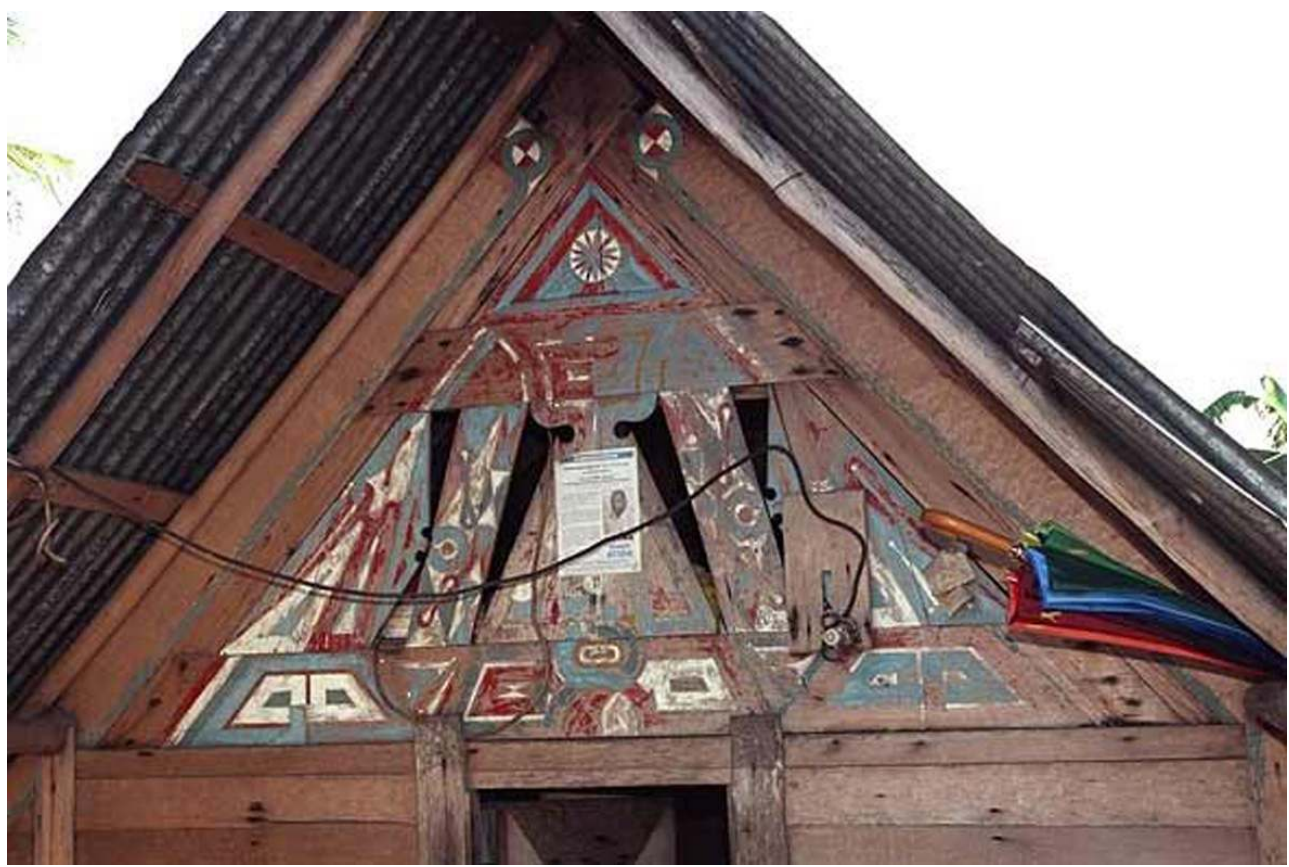

Détail d'un pignon découpé et peint, Kotika (rive gauche du Lawa)

Phot. Inv. M. Heller @ Inventaire général, ADAGP, 2001

\section{Constructions des campu}

Aux maisons permanentes des villages s'opposent celles des campu, plus petites, plus modestes et souvent sans décor. Elles ne contiennent pas de mobilier : hamacs, platine à couac et objets culinaires sont apportés du village permanent à chaque séjour.

On trouve dans ces lieux d'habitat temporaire des constructions peu soignées : cabanes en planches montées à clin et couvertes en tôle, mais également des maisons entièrement montées en feuilles de waï tressées, destinées à durer quelques années seulement ou peut-être à être déplacées (fig. $\mathbf{n}^{\circ} 18$ et 19). Ces constructions extraordinaires témoignent d'un savoir-faire original qu'il faudrait préserver. Enfin, on trouve également dans les campu djuka des maisons d'allure traditionnelle bien bâties, ce qui s'explique par l'émigration vers la rive française et le fait que d'anciens campu deviennent des villages permanents. 
Figure 18

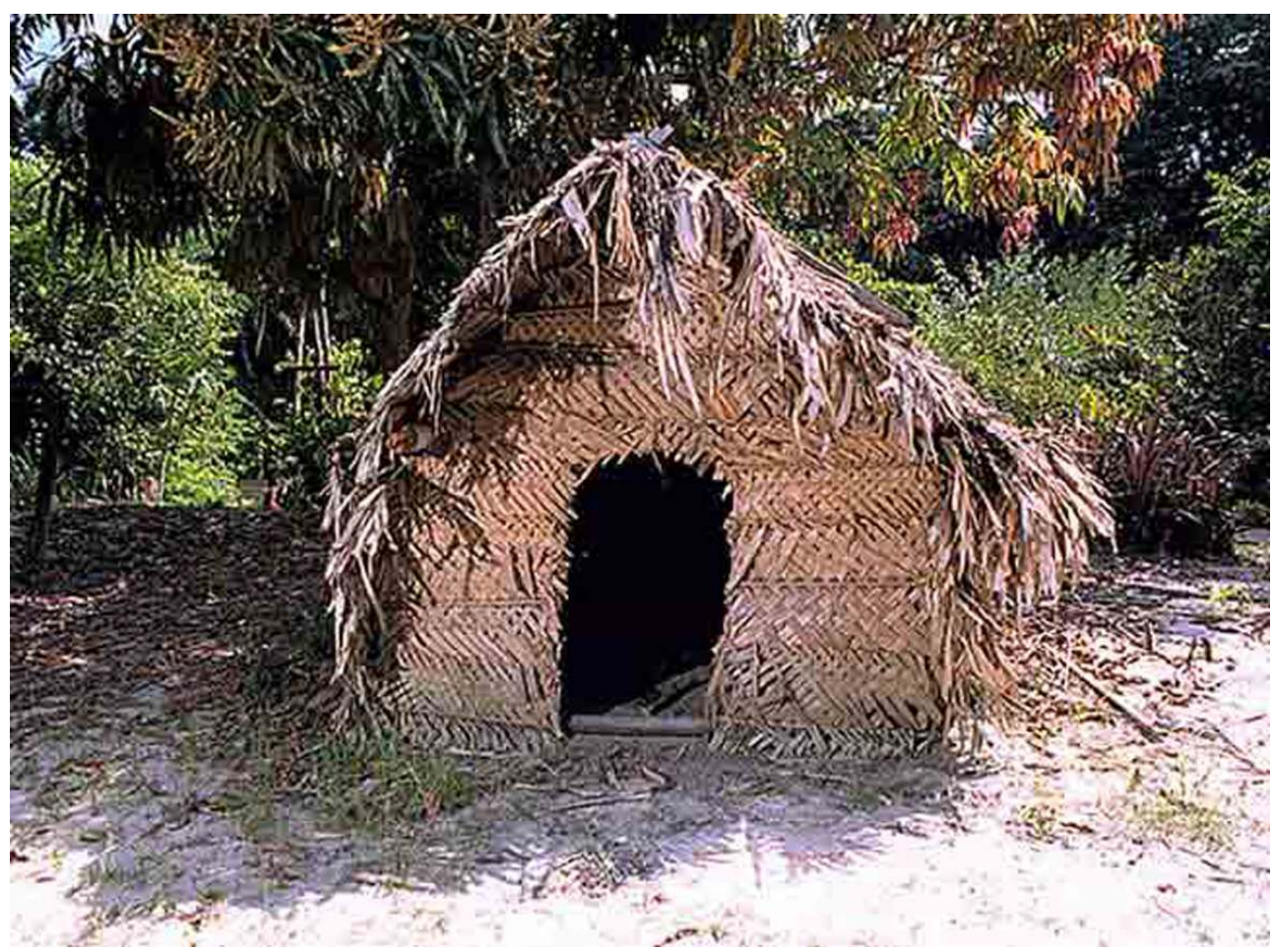

Construction en feuilles de waï dans un campu. Vue extérieure

Phot. Inv. M. Heller @ Inventaire général, ADAGP, 2001

Figure 19

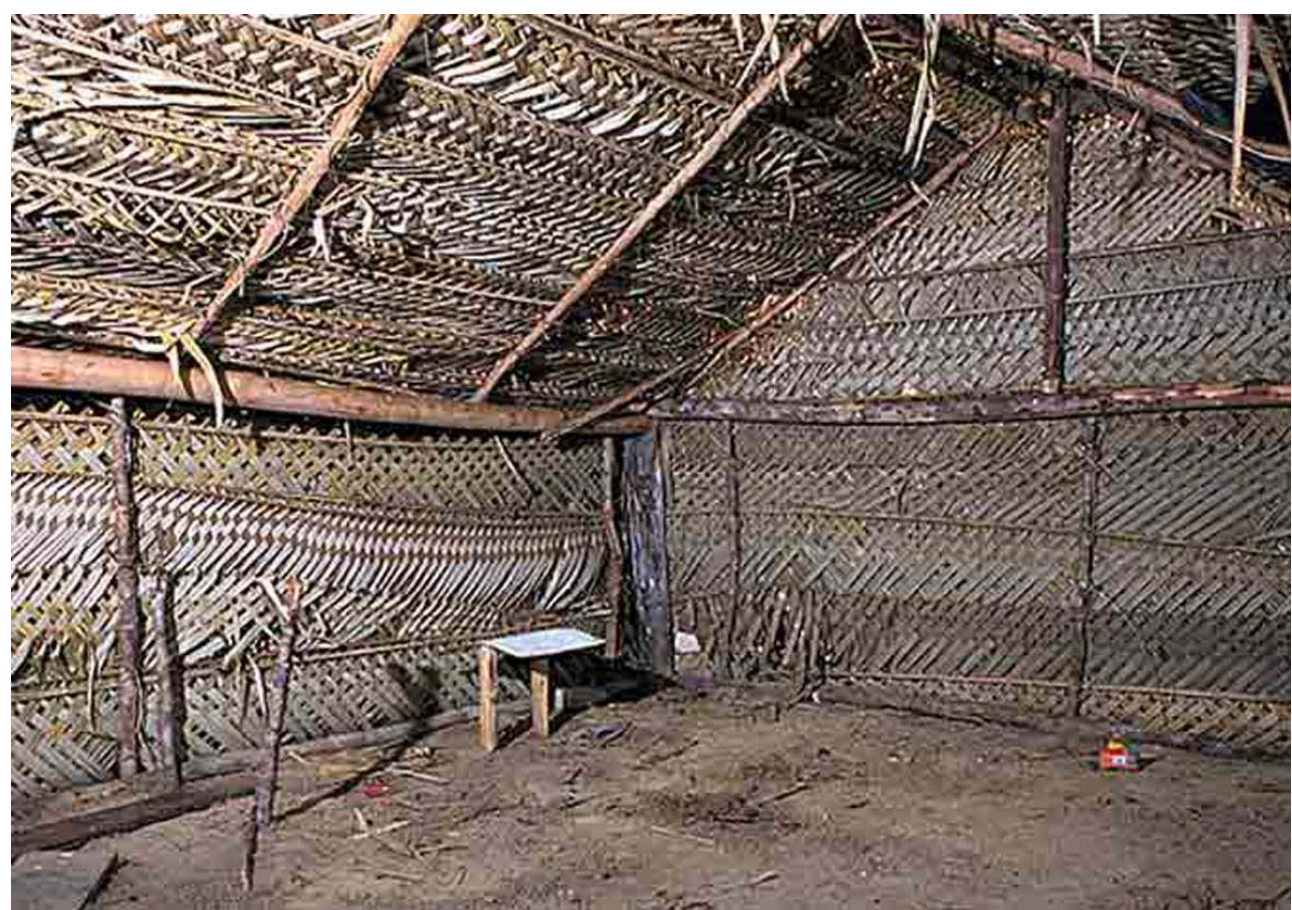

Construction en feuilles de waï dans un campu. Vue intérieure

Phot. Inv. M. Heller @ Inventaire général, ADAGP, 2001 


\section{Evolution actuelle}

L'évolution actuelle de l'habitat des noirs marrons témoigne à la fois des profondes mutations que connaissent ces sociétés et d'un grand attachement à la tradition, même chez les Aluku français, dont le mode de vie communautaire a été profondément bouleversé.

\section{Figure 20}

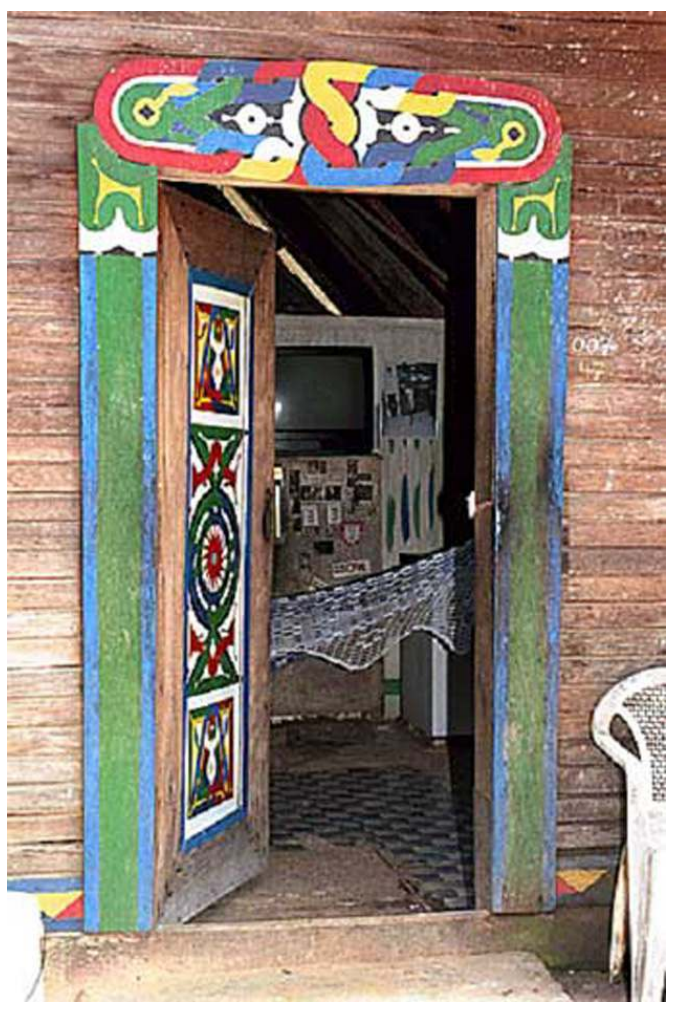

Cette porte d'une maison récente d'Apatou est de taille européenne mais peinte d'un tembé. On entrevoit l'aménagement intérieur : linoleum, télévision et hamac

Phot. Inv. M. Heller @ Inventaire général, ADAGP, 2001

Les villages du Lawa se dépeuplent en partie au profit d'Apatou et Saint-Laurent. Les habitants restés sur place ont parfois un travail salarié et bénéficient des prestations sociales françaises conçues pour une famille mono nucléaire. Les hommes salariés ont moins de temps pour construire une maison très décorée à leur femme et considèrent parfois que celle-ci, percevant les allocations familiales, a les moyens de se loger sans leur $a^{a i d e}{ }^{16}$. Le système de l'abattis fondé sur la complémentarité des rôles féminin et masculin est en retrait et d'une manière générale le statut des hommes est à redéfinir.

De plus, la fréquentation des métropoles du littoral, Saint-Laurent, Cayenne ou Paramaribo a fait évoluer l'idée que l'on avait de la maison. Ce que l'on considère aujourd'hui comme une belle demeure s'inspire de formes étrangères, comme les maisons de bois en kit ou les maisons en parpaings, que l'on construit soit sur de nouveaux sites qui prennent parfois l'allure de lotissements (New-Wacapou, New-Assissi), soit à la périphérie des villages, soit autour de la maison elle-même ${ }^{17}$. Pourtant, dans les nouvelles constructions, on retrouve le même souci d'harmonie. La façade est toujours l'objet d'une 
ornementation qui en souligne les éléments structurels (fig. $\mathbf{n}^{\circ}$ 20) même si c'est désormais la porte d'entrée plus que le pignon (réduit par l'élévation des façades latérales) qui concentre le décor sculpté ou peint.

Figure 21

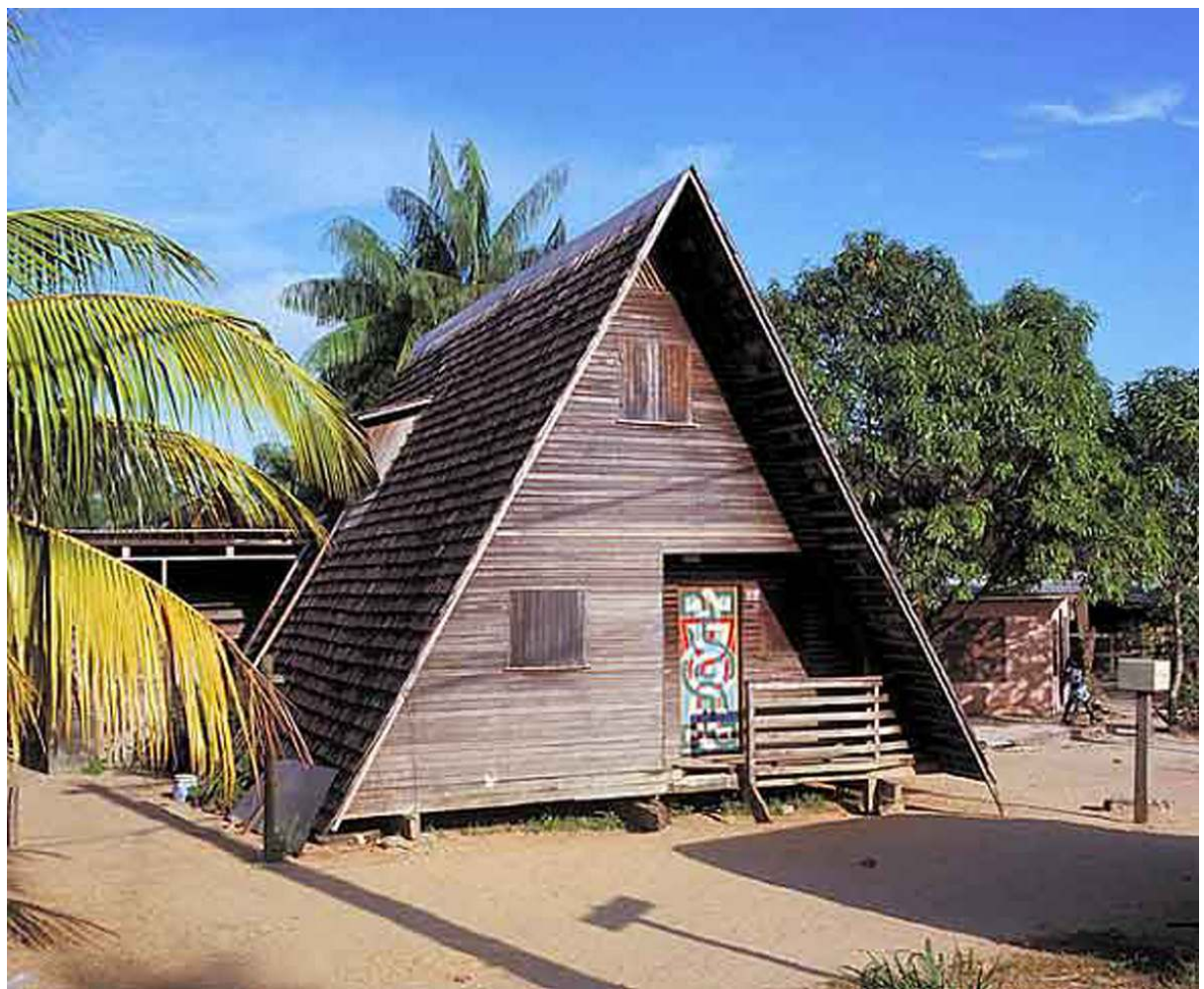

Une maison de la Charbonnière, banlieue noir-marron de Saint-Laurent Phot. Inv. M. Heller (c) Inventaire général, ADAGP, 2001

Les maisons aluku d'Apatou sont encore pour la plupart des constructions «traditionnelles » par leurs proportions et leur décor. Actuellement, les noirs marrons enrichis par l'orpaillage ont tendance à recourir aux maisons en bois préfabriquées importées du Surinam avec plusieurs pièces et véranda, voire au parpaing, ou, dans les zones pauvres, à des constructions en planches montées à clin et couvertes de tôle. Il est nécessaire de revaloriser l'image de la maison traditionnelle, à l'exemple de ce qui a été tenté à La Charbonnière, cité noir-marron créée par les pouvoirs publics au sud de SaintLaurent (fig. $\mathbf{n}^{\circ} \mathbf{2 1}$ ).

\section{Conclusion}

A partir de ces premières enquêtes, encore très superficielles, se dégage une grande parenté entre les maisons aluku et djuka, bien que ces groupes se soient constitués à des époques différentes, avec des populations venant probablement de plusieurs régions d'Afrique. Cette première impression resterait à affiner et à préciser par l'étude des «grands villages» du Tapanahony, d'autant plus importante que les villages djuka apparaissent plus traditionnels que les villages aluku, surtout ceux de la rive surinamienne. 
40 patrimoine guyanais que l'on souhaiterait pouvoir conserver. Cette notion de conservation est assez étrangère aux Noirs marrons, mais pourrait devenir un jour importante pour leurs descendants émigrés à Saint-Laurent, Cayenne ou Kourou.

\section{NOTES}

1. Sur l'organisation sociale encore communautaire du milieu du $\mathrm{XX}^{\mathrm{e}}$ siècle, cf. Hurault, Jean. Les Noirs réfugiés boni de la Guyane française. Mémoires de l'Institut Français d'Afrique noire. Dakar: I.F.A.N., 1961. Du même auteur, La vie matérielle des Noirs réfugiés boni et des Wayanas du haut Maroni (Guyane française) : agriculture, économie et habitat. Paris : ORSTOM, 1965, ainsi que Africains de Guyane. La vie matérielle et l'art des noirs réfugiés de Guyane. Paris-La Haye : Mouton, 1970. Sur les mutations récentes, Aubert, Carole. L'habitat des bushi-nenge du Maroni en Guyane française. (dir. P. Erny). Cultures et habitat. Douze contributions à une ethnologie de la maison. Coll. Culture et Cosmologie. Langres, 2000, p. 42-60 ; Aubert, Carole, Brasselet, Franck, Joseph, Jean-Pierre, Chevalier, Yves. Etude pour un habitat adapté aux sites isolés de Guyane. Rapport dactyl., CAUE de Guyane. Cayenne, 1996 ; BILBY, Kenneth. Les Boni et les communes, un problème d'intégration. Equinoxe, $\mathrm{n}^{\circ} 24$; Hublin, Anne. La prolétarisation de l'habitat des Marrons de Guyane. MELATT, Bureau de la recherche architecturale. Paris : Ecole d'architecture de Paris-Villemin, 1987.

2. Ou un fragment de lignage. Jean Hurault cite par exemple le cas du lo Dipélou présent à Kormontibo vers 1880 qui a fait scission : une partie s'est installée à l'Enfant perdu (Tabiki); le village d'Assissi est formé de trois quartiers qui correspondent à trois lo différents.

3. Tous les individus séparés d'une aïeule par le même nombre de générations se nomment frères et sœurs alors que dans le système européen ils seraient cousins à des degrés divers.

4. Terrain préparé pour la culture, après débroussaillage et brûlis, mais sans que les souches d'arbre soient retirées.

5. Nous employons la graphie Djuka, la plus communément utilisée en Guyane française, et non Ndyuka, plus fidèle à la prononciation, comme Richard et Sally Price, Les Marrons. Coll. Cultures en Guyane. Châteauneuf-le-Rouge : Editions Vents d'Ailleurs, 2003.

6. Pour plus de détails, voir Richard et Sally Price. Les Marrons. Coll. Cultures en Guyane. Châteauneuf-le-Rouge : Editions Vents d'Ailleurs, 2003.

7. L'unité familiale et économique de base formée par la mère et ses enfants s'appelle le bobi.

8. Cité par Le Roux, Y. L'habitation guyanaise sous l'Ancien Régime. Thèse dactyl. Paris : Ecole pratique des Hautes Etudes, 1996.

9. Contrairement à Carole Aubert, nous n'avons pas noté dans les quelques maisons visitées de différence évidente entre les deux pièces. La première contient toujours un ou plusieurs hamacs et sert donc de chambre à coucher, peut-être réservée aux enfants.

10. C'est le seul exemple d'objet en céramique recensé dans ces sociétés ; les Noirs marrons n'en fabriquent pas mais utilisent des calebasses.

11. Palmier dont les feuilles sont cousues sur des baguettes. Les bandes végétales ainsi constituées sont placées parallèlement au faîtage.

12. Alors que les Kalina utilisent les feuilles du palmier maripa disposées perpendiculairement au faîtage. 
13. Hurault, Jean. Africains de Guyane. La vie matérielle et l'art des noirs réfugiés de Guyane. Paris-La Haye : Mouton, 1970, p. 40, mais cela pourrait également être une réminiscence africaine.

14. Aubert, Carole. L'habitat des bushi-nenge du Maroni en Guyane française. (dir. P. Erny). Cultures et habitat. Douze contributions à une ethnologie de la maison. Coll. Culture et Cosmologie. Langres, 2000, p. 193.

15. Hurault, Jean. Africains de Guyane. La vie matérielle et l'art des noirs réfugiés de Guyane. Paris-La Haye : Mouton, 1970, planche 12.

16. D'après Carole Aubert, à New-Assissi, les propriétaires de maison sont des femmes, qui ont elles-mêmes financé leur demeure dans $70 \%$ des cas.

17. Nous avons pu voir en 2002 deux maisons en parpaings de grande taille en cours de construction autour de la demeure en bois originelle. Celle-ci ne serait détruite qu'une fois le nouvel édifice achevé.

\section{RÉSUMÉS}

Le long du Maroni, fleuve frontière entre la Guyane française et le Surinam, vivent les Aluku et les Djuka, descendants des esclaves marrons échappés aux XVIII ${ }^{\mathrm{e}}$ et XIX $\mathrm{X}^{\mathrm{e}}$ siècles des plantations de la Guyane hollandaise. A l'écart des colons occidentaux, ils ont développé des cultures originales, mélanges de traditions des sociétés africaines dont ils étaient issus et d'emprunts aux Amérindiens. Malgré les bouleversements actuels, leur habitat reste un témoin remarquable de cette histoire absolument originale.

By the Maroni river, which is the border beetwen French and Dutch Guyanas, live the Aluku and the Djuka, descendants from marroon slaves escaped from Suriname plantations. Far from european settlers, they developped original cultures, which mixed african traditions and Amerindian elements. In spite of recent changes in the way of life, their architecture is still a testimony of their original history.

\section{INDEX}

Mots-clés : Aluku, Boni, Djuka, Guyane, Maroni, Businengé, Campu

\section{AUTEUR}

\section{MARIE-PASCALE MALLÉ}

Conservatrice en chef du patrimoine, Musée national des Arts et Traditions populaires-antenne de préfiguration du Musée des civilisations de l'Europe et de la Méditerranée, Marseille. marie.pascale-malle@culture.gouv.fr 